\title{
O que a comparação entre a tradição religiosa e os novos movimentos religiosos nos ensina sobre o sujeito hoje?
}

\author{
Anna Carolina Lo Bianco \\ Universidade Federal do Rio de Janeiro
}

\begin{abstract}
Resumo
O artigo toma a distinção feita por Freud (1939/1996) em "Moisés e o monoteísmo", entre uma tradição herdada e uma tradição comunicada, para comparar alguns traços das religiões tradicionais com características dos novos movimentos religiosos. Usando os recursos epistemológicos que mais tarde foram desenvolvidos por Lacan, observa que a religião monoteísta mantém relação com uma tradição herdada, pondo em cena um real. Argumenta que tanto essa relação quanto a tradição foram perdidas nas práticas das seitas atuais. Conclui que devido ao afastamento dessa dimensão que remete a um real, as novas práticas religiosas recebem uma inflexão que as coloca ao lado da mera prescrição comportamental, fazendo de seus adeptos, sujeitos de uma nova economia psíquica.
\end{abstract}

Palavras-chave: psicanálise; religião; novos movimentos religiosos; tradição; sujeito

\begin{abstract}
Religious tradition and the new religious movements compared: a vision about the subject today. The article resumes the distinction referred to by Freud (1939/1996) in the text "Moses and Monotheism" between an inherited tradition and a tradition transmitted by communication. Uses this distinction in order to compare some traits of traditional religions with characteristics of the new religious movements. Utilizes epistemological tools developed by Lacan to observe that the monotheistic religion is related to the inherited tradition - the one that supposes the dimension of the real. This tradition and the relation that it entails were lost in the sectarian practices of today. It concludes that due to the fact that they are not related to the dimension of the real new religious practices become subject to mere behavior prescription. Their followers being subjects to a new psychic economy.
\end{abstract}

Keywords: psychoanalysis; religion; new religious movements; tradition; subject

B asta uma superficial olhada na paisagem das principais cidades brasileiras, para se ver a profusão de monumentais construções que abrigam um sem número de templos das mais variadas seitas. Surgidas, em geral, há menos de duas décadas, apontam para a ubiqüidade do que se designa como novas formas de religião. Esses movimentos religiosos, por sua vez, parecem responder a novas formas de subjetividade. Procuramos, através de um olhar psicanalítico, localizar, no constante recurso a tais religiões e no sucesso que vêm alcançando, uma importante dimensão do que Melman (2002) chama a "nova economia psíquica".

Recorremos ao texto de Freud (1939/1996), "Moisés y la religión monoteísta", para que numa comparação com o que ele forjou como a fundação da religião judaica possamos melhor conceituar o que se passa com os novos movimentos religiosos. Deste texto, tomamos a distinção entre uma tradição herdada e uma tradição comunicada (p. 96), utilizando-a como ponto de apoio para pensar alguns traços da religião e da cultura judaicas estudadas por Freud e confrontá-los com características das novas religiões na atualidade. Depreendemos daí que a religião monoteísta de base judaica mantém relação com uma tradição herdada; relação e tradição que foram perdidas nas práticas das referidas seitas. Usando os recursos epistemológicos que mais tarde nos foram dados por Lacan, supomos que, por conta de uma desconsideração do que a psicanálise toma como a dimensão do real (ver Lacan, 1970/2003, por exemplo), essas práticas religiosas recebem uma inflexão que as coloca ao lado da mera prescrição comportamental. Encontram-se afastadas, portanto, da dimensão simbólica que se podia reconhecer nas religiões até então, ainda que tais religiões sempre estivessem arrebatadas pelo sentido divino atribuído à vida. A inflexão sofrida pelas seitas, procuraremos argumentar, é tributária das maneiras atuais de se estar em cultura, que têm nessa modalidade de relação com o real uma de suas características mais pregnantes.

No desenvolvimento das hipóteses de Freud sobre a origem do monoteísmo circunscrevemos, de início, um de seus pressupostos mais caros, enunciado em "Psicologia das massas e análise do eu" (Freud, 1921/1996), que afirma não 
haver diferença entre o social e o individual. Admitindo que o "individual é simultaneamente o social" (p. 67), vê uma coincidência entre o que se passa, por exemplo, com o gênero humano e o que se passa na vida dos indivíduos. Por isso, ao falar da fundação de uma religião, pode valer-se dos mesmos conceitos usados em toda a trajetória da construção da psicanálise.

Localiza, então, o trauma - o mesmo conceito que fala das marcas precoces infantis; que se refere às marcas feitas no corpo por impressões vistas e ouvidas que não podem fazer parte das associações, que não são significantizáveis, não são articuláveis - como o ponto em torno do qual virá a ser elaborada a história do sujeito, tanto quanto a história da cultura ou de uma religião como o judaísmo. Sendo impossível conviver com essas marcas por sua intensidade, pelo excesso que portam, pelos seus efeitos de ruptura, por sua insistência, elas serão desmentidas. No entanto, mesmo assim, ficam como cicatrizes. São indicadores das intempéries pelas quais o corpo passou, e é pela elaboração de tais marcas que o sujeito vem tomar lugar em sua própria história.

Freud (1939/1996) irá se servir dessa "fórmula" (p. 77) do desenvolvimento da neurose na construção que fará acerca da formação da religião judaica. Acredita que essa construção possa mostrar a "genuína natureza de uma tradição" (p. 51) que traz os efeitos do trauma sentido através das gerações. Trata-se de uma tradição marcada pelo trauma e pelo que ele traz de inassimilável e de irrecuperável.

Faz assim uma correção importante na concepção de tradição, que, em lugar de trazer uma idéia de continuidade - responsável pela passagem de conteúdo comunicado de pais para filhos - passa a ser considerada sob o ponto de vista da elaboração a posteriori (nachträglichkeit). A tradição herdada implica rupturas e reversões que permitem um novo entendimento acerca da firmeza e da intensidade dos afetos transmitidos. A força da tradição passa a ser entendida através de um domínio que ultrapassa a simples comunicação de fatos apreendidos e vivenciados pelas gerações anteriores, indo além de uma "tradição que se propaga por mera comunicação" (Freud, 1939/1996, p. 96). Para abordar uma tradição assim herdada, Freud lança mão da idéia de que o herdado pelas gerações mais novas, o foi com base no "desenvolvimento biológico de caracteres adquiridos” (p. 96), não necessariamente comunicados pelos mais velhos, não necessariamente vivenciados pelo próprio indivíduo, mas trazidos pelo nascimento - uma "herança arcaica" feita de "fragmentos de origem filogenética" (p. 94).

Voltaremos a essa afirmação que se torna mais controversa quanto mais a idéia de transmissão filogenética é criticada e novas conceituações se tornam disponíveis ao longo do século XX. Antes, no entanto, nos deteremos no que já foi considerado o "ato freudiano" (Harly, 2002), ou seja, sua decisão de sair ao encontro dos acontecimentos que estariam na base de toda a sua construção acerca da religião mosaica. Vemos Freud perseguindo com total obstinação o que acreditava se constituísse o fator diferencial do edifício psicanalítico quando comparado aos sistemas de pensamento filosófico e metafísico. Procura recuperar com base nas mais variadas fontes, atrás dos mais antigos relatos e dos mais diminutos detalhes os "fósseis de referência" (p. 38), o acontecer histórico (Geschichte) que lhe permitisse construir a história da fundação da religião judaica. Como comenta Lacan (1970/2003), recorta por seu procedimento um real para a religião mosaica, ao procurar dar as bases da tradição que a tornou possível - a tradição que garantiu a transmissão do trauma vivido pelo povo judeu. Vale dizer, Lacan surpreende, no ato freudiano, a sua decisão de, ao conceber a tradição herdada, circunscrever o real que está em sua fundação.

Não é possível exagerar quando nos referimos ao cuidado e à minudência com que Freud reescreve a história de Moisés, recorrendo detalhadamente a todos os argumentos disponíveis para justificar sua construção e sustentar a hipótese de que há algo além dos relatos difundidos e comunicados sobre a saga do povo judaico. Seguiremos a conhecida elaboração freudiana apenas para ressaltar sua reflexão sobre a transmissão dessa tradição através dos séculos.

É assim que vemos Freud valorizando os dados que levam à configuração de um Moisés aristocrata do Egito, que seguia a religião do faraó Akenaton. Religião que se destacou de toda a prática religiosa egípcia, até então, por sua crença num único deus, mas que foi abandonada com a morte do faraó. Moisés, no intuito de seguir professando a religião que adotara, elege um grupo de semitas e o conduz a um novo lugar onde poderiam continuar a crença monoteísta. Em sua pesquisa, nesse ponto, Freud encontra as evidências que, por vários motivos, haviam sido apagadas e lhe permitem reencontrar a encenação de um novo assassinato perpetrado contra uma figura de autoridade. $\mathrm{O}$ povo ao se confrontar com as exigências e a severidade de seu guia se revolta contra ele e o mata. Retornam em seguida à crença politeísta e Moisés passa a ser um estrangeiro que os conduziu à nova terra. Tempos depois - Freud continua a construção da trama - em Cádis, encontram uma tribo que adorava o deus Javé e elegem um novo guia, de origem medianita que também se chamava Moisés. Nesse ponto, as duas religiões se misturam e selam um compromisso entre a antiga religião do grupo e a religião medianita que adorava o deus vulcânico Javé.

Desse momento até aquele em que o autor (Freud, 1939/1996) reconhece como o "triunfo do Deus mosaico sobre Javé" (p. 49), encontra dados que lhe confirmam que, nesse mesmo povo, "ergueram-se as vozes de homens que não estavam ligados a Moisés desde o início. Haviam sido, na verdade, cativados por essa tradição grande e poderosa que pouco a pouco havia crescido nas sombras" (p. 49) e era relacionada com o assassinato de Moisés e com o pedido feito pelo Deus mosaico (veiculado pelo próprio Moisés) de uma vida em verdade e em justiça. Deixando de lado o sacrifício e o cerimonial característicos da religião de Javé, o povo judeu recobrou a palavra que lhe havia sido dirigida e a partir daí soube conservar a crença num só Deus.

A idéia de uma tradição "grande e poderosa" que "cresce na sombra" lança luz sobre a operação de transmissão entre gerações que sustenta a história da religião judaica durante tantos séculos. É importante, ainda, enfatizarmos a insistência de Freud na lacuna que ocorre entre o assassinato de Moisés e a entrada em vigor das doutrinas mosaicas que terminaram por se impor ao povo judaico. Se uma parte desse povo havia tido uma vivência valorizada como traumática - a de haver assassinado aquele que exigia deles a fé em seu deus - e a outra parte não teve acesso a ela, em ambas mostrava-se o "mesmo interesse por desmentir 
que haviam tido uma religião anterior" (p. 66). O compromisso firmado na nova religião, Freud (1939 /1996) argumenta, teria mesmo ganho uma fixação escrita que se esforçava por não trazer à tona o passado, mantendo uma lacuna no lugar onde estaria a verdade sobre suas origens. No entanto, diz ele, "o omitido ou modificado na transcrição, pode muito bem conservar-se intacto na tradição" (p. 66). Justamente porque o que havia sido guardado pela tradição não estava em primeiro plano, podia ser preservado das "tendências desfiguradoras" que incidiam sobre a historiografia (p. 66).

Freud (1939/1996) ressalta que a tradição, além disso, não fora apagada sem deixar "rastros" (p. 67). A partir deles, como veremos, a religião de Moisés conseguiu exercer um efeito poderoso sobre a vida anímica do povo e, ao fim, pôde ganhar expressão. A tradição comporta "fragmentos do acontecer histórico" (p. 81) que, mesmo não tendo sido vividos pelos próprios indivíduos, lhes foram dados no nascimento. Tratase da herança arcaica, como vimos, e Freud atribui a esses fragmentos uma origem filogenética. A herança arcaica abarca não só predisposições constitucionais herdadas pelo indivíduo, mas também conteúdos, ou seja, "marcas mnêmicas do que foi vivenciado por gerações anteriores" (p. 94). Essa herança - e aqui encontramos mais uma vez o ponto central em que estamos apoiando nosso argumento sobre o real em questão no escrito freudiano - independe de sua comunicação direta ou da influência da educação. Fosse ela simplesmente comunicada, a religião seguida pelo povo judaico não teria se mantido viva durante todos esses séculos.

Como dissemos, a idéia de uma tradição, assim, arcaica levanta de imediato a suspeita de um Lamarckismo insustentável, que, além disso, serve de motivo para uma série interminável de discussões sobre a atualidade ou o inatual do pensamento freudiano (ver, por exemplo, Bernstein, 1998). Lacan (19691970/1991) mesmo, mencionando essa idéia de uma transmissão através dos cromossomas, fala que "Moisés é o cúmulo dos cúmulos" (p. 132), para em seguida perguntar por que, no entanto, "Freud precisou de Moisés" (p. 129). Não pretendemos, no âmbito desse trabalho, responder a essa interrogação, tarefa árdua que vem consumindo o trabalho de tantos analistas ao longo dos anos (ver, por exemplo, Balmès, 1997; Lemérer, 1997; Rabinovich, 1997). Encaminharemos a questão, apenas na medida em que ela nos auxilia a considerar a transmissão em sua relação com um real cuja operação podemos reconhecer nas religiões tradicionais, como a judaica, para compará-la com o que se coloca em jogo nos novos movimentos religiosos.

Freud precisa de Moisés, da mesma forma como precisa do assassinato do pai em "Totem e tabu" (Freud, 1913/1996) e dos desafios que enfrenta Édipo. Vê em todos - em Moisés, como no pai da horda e em Édipo - personagens de histórias que faz questão de sustentar como sendo reais, valendo-se delas ademais pela "extraordinária latência" que contêm. Cada uma dessas histórias veicula a mesma interrogação sobre a transmissão; e, de acordo com a perspectiva que nos orienta, podemos afirmar, sobre a transmissão em sua relação com algo que se perde de uma geração a outra. Essa interrogação cativa Freud e o faz recolher, em algum lugar do texto de Sellin (1922, apud Freud, 1939/1996), no qual se baseia para escrever sobre Moisés, o assassinato que deixa a marca de um trauma.

Freud enfatiza essa marca, dando-lhe o valor de um fóssil, de um referente a partir do qual vai passar à construção do real do judaísmo. Nessa construção está menos preocupado com a exatidão dos fatos do que com a justeza (Lemérer, 1997), com a certeza que ela permite relevar acerca do que constitui a tradição judaica. Reconhecendo traços indeléveis e imortais do trauma, que insistem em não se deixar inscrever, reconhece, ao mesmo tempo, o poder da transmissão. A cada vez que esses traços são reanimados, são atualizados, a cada nova tentativa de retomálos, de conquistá-los, encontramos a transmissão em operação. É nessa submissão à transmissão, momento em que o sujeito surge na cadeia das gerações - pela conquista, pela elaboração do que foi herdado das gerações anteriores - que localizamos a tradição a que se refere Freud quando fala da força da cultura e da religião judaicas pelos séculos afora. $\mathrm{O}$ sujeito emerge nelas pelo pagamento de um tributo ao que herdou. Dito de outra forma, é assujeitado à sua história, para a construção da qual só conta com os traços, com os fragmentos, com o enigma que recebeu como herança.

É muito diferente uma religião que se forja por uma tradição assim herdada, em que a construção de sua história é feita a partir desses traços - construção que ademais é também a tarefa de uma análise - de outra em que as estórias são simplesmente ouvidas através de um comunicado ou por meio de uma peroração exaltada. Enquanto numa reconhecemos a tradição herdada de que fala Freud, na outra temos uma tradição que se propaga por comunicação. São duas formas de encararmos a relação de uma religião com os traços que habitam o seu real. Enquanto numa podemos apontá-lo, podemos indicá-lo como o lugar em que a causa da religião está em jogo, na outra ele é desconsiderado.

Desconsiderar o impossível que o real impõe é o que vemos acontecer nas novas religiões que se recusam a pensar os seus fundamentos, substituindo-o pela palavra de ordem de um líder do momento, ou mesmo da exibição de alguns dons de cura que esse manifesta. Tal maneira de relação ao real, que não o toma em seus efeitos desconcertantes sobre um fiel sempre responsável por seus atos, é contemporânea das relações que mantém com a religião a multidão de indivíduos que vão buscar nela a receita para a cura de seu mal-estar no cotidiano (Lacôte, 2001).

As seitas que hoje encontramos, muitas vezes chegam a afirmar não terem uma teologia, não terem um fundamento, pelo qual tenham de responder e o qual tenham de suportar e ao mesmo tempo defender. Deixam de lado, dessa forma, a dimensão do real que as funda.

Baseando-nos no trabalho etnográfico extremamente cuidadoso e abrangente de Giumbelli (2002), podemos esboçar algumas idéias que nos ajudam a desenvolver um pouco mais o que se passa nesses movimentos que surgem com tanta intensidade. Partindo delas, tentamos avançar no que chamamos, com Melman (2002), a "nova economia psíquica" que caracteriza os fiéis que buscam esses grupos.

A idéia de uma tradição qualquer é afastada e os novos movimentos religiosos se caracterizam por apresentarem uma série de conteúdos inventados a cada ocasião, havendo um acentuado descompromisso com as origens históricas e uma completa "liberdade" na formulação de novas propostas 
doutrinárias e de novas formas de organização religiosa. Encontra-se nessa desconsideração da dimensão histórica um deslocamento de ordem teológica - inovações teológicas são introduzidas ao sabor dos interesses mais imediatos, tendo em vista, muito provavelmente, o sentido de angariar um maior número de simpatizantes.

Seguindo os estudos de Giumbelli (2002), pelo menos duas características apresentadas nessas inovações podem nos orientar na tentativa de aproximarmo-nos daquilo de que se trata para os adeptos das seitas: em primeiro lugar, ressalta uma preocupação com a "adaptação" ao mundo moderno. Trata-se de uma reação aos novos valores e hábitos que "exigiriam" novas posturas, por parte daqueles que guiam os fiéis.

Em segundo lugar, em decorrência dessas novas doutrinas, uma vez que os enunciados doutrinários surgem no momento, o que se torna uma característica fundamental é o carisma de um líder de ocasião e sua capacidade de comunicação. Ou seja, precisamente nesse ponto estamos no terreno da comunicação e não da enunciação. O importante, então, é a capacidade de comunicação, i.e., a capacidade de operar com a massa de indivíduos que seguem esse líder.

Por um lado, então, temos a tradição colocada de lado, a busca da adaptação ao que é visto como exigência do mundo moderno e o carisma do líder que se encarrega de guiar os adeptos. De outro lado, temos adeptos a um modo de satisfação imediato que buscam, para consegui-la, a via dos bens de serviços: por isso as igrejas vivem e proliferam através do dízimo. Dízimo que, segundo as testemunhas (Giumbelli, 2002), são ainda maiores quando se procura uma salvação ou uma cura. Os fiéis são então cobrados pelo que procuram. Tudo se passa numa dimensão de troca: eles pagam para obter um milagre e são incentivados a cobrarem de Jesus a operação dos milagres pelos quais pagaram. Há relato de igrejas em que se encontra na porta o aviso: "seu milagre garantido ou seu dinheiro de volta". É interessante pensarmos quão distante tal postura está da situação como a que nos referimos, anteriormente, em que Moisés exigia do povo judaico uma vida em verdade e em justiça, não importando às custas de que sacrifícios.

Acreditamos, portanto, que para além das semelhanças que unem religiões tradicionais e movimentos religiosos recentes marcados todos pela mesma busca da felicidade e do alívio para o mal-estar, ou seja, articulados todos para garantir os meios de apaziguamento do sofrimento - há diferenças acentuadas entre ambos. Defrontamo-nos, de um lado, com sujeitos a uma religião que aponta para um real traumático (que exige dele trabalho e elaboração subjetiva), por outro lado, estamos frente ao sujeito (se podemos chamá-lo assim) dessas novas religiões que se oferecem como prestadoras de serviços e bens e vivem de fazer promessas de satisfação a curto prazo. São, pois, os sujeitos da nova economia psíquica, formulada por Melman (2002), aqueles que operam no nível da troca - da busca de uma satisfação inadiável - tornando-se presas de manipulações e de injunções impostas numa dimensão superficial e puramente comportamental. Esperam somente alguém para vir e lhes dizer o que deve ou não ser feito, o que é bom ou não para obterem a satisfação plena. Diferentemente do sujeito das religiões tradicionais, em relação a quem se observa a crença fundada num real transmitido, encontramos nos membros das seitas uma convicção cega acerca do saber e da autoridade de um fundador encarnado que vem permitir o encontro com os objetos de satisfação. Justamente uma satisfação que não reconhece distinções ou que não diferencia esses objetos, todos passando a ter o mesmo valor de mercadoria a ser consumida, considerada apenas enquanto serve como meio de obtenção imediata dessa satisfação. Estamos, pois, frente à economia em que o objeto não é mais aquele da pulsão - o objeto que se perde com a instauração da linguagem -, mas aquele supostamente encontrado, da esperança de conforto e de reconforto imediatos, garantia da promessa de um gozo sem limites.

\section{Referências}

Balmès, F. (1997). Le nom, la loi, la voix: Freud et Moïse ecriture du père. 2. Paris: Érès.

Bernstein, R. J. (1998). Freud e o legado de Moisés. Rio de Janeiro: Imago.

Freud, S. (1996). Totem y tabu. In Obras completas (Vol. XIII, pp. 1-164). Buenos Aires: Amorrortu. (Texto original publicado em 1913)

Freud, S. (1996). Psicología de las masas y análysis del yo. In Obras completas (Vol. XVIII, pp. 63-136). Buenos Aires: Amorrortu. (Texto original publicado em 1921)

Freud, S. (1996). Moisés y la religión monoteísta. In Obras completas (Vol. XXIII, pp. 1-132). Buenos Aires: Amorrortu. (Texto original publicado em 1939)

Giumbelli, E. (2002). O fim da religião: dilemas da liberdade religiosa no Brasil e na França. São Paulo: Attar.

Harly, A. (2002). Le Moïse, un acte freudien. Obtido em http://www.freud-lacan. com, em 20 de agosto de 2002.

Lacan, J. (1991). Le Seminaire, Livre XVII: l'envers de la psychanalyse. Paris: Seuil. (Texto original publicado em 1969-1970)

Lacan, J. (2003). Radiophonie. Pergunta VII. In Outros escritos. Rio de Janeiro: J. Zahar. (Texto original publicado em 1970)

Lacôte, C. (2001). Expressions contemporaines du "besoin" religieux. Bulletin de l'Association Freudienne Internationale, 92, 3-7.

Lemérer, B. (1997). Les deux Moïse de Freud (1914-1939): Freud et Moïse ecriture du père 1. Paris: Érès.

Melman, C. (2002). L'Homme sans gravité. Jouir à tout prix. Paris: Denoël.

Rabinovich, S. (1997). Écritures du meurtre: Freud et Moïse ecriture du père 3. Paris: Érès.

Sellin, E. (1922). Mose und seine bedeutung für die israelitischjüdische Religionsgeschichte. Leipzig \& Erlangen: A. Deichertsche Verlagsbuchhandlung.

Anna Carolina Lo Bianco Clementino, doutora em Psicologia pela Universidade de Londres (Reino Unido), é professora associada na Universidade Federal do Rio de Janeiro. Endereço para correspondência: Programa de Pós-graduação em Teoria Psicanalítica (IP/UFRJ); Av. Pasteur, 205; Rio de Janeiro, RJ; CEP: 22290-240. Tel.: (21) 3873-5343. E-mail aclobianco@uol.com.br 